\title{
Research on the Relationship between Transportation Infrastructure and Regional Tourism Economy
}

\author{
Dongxuan Fan $^{1, *}$ \\ ${ }^{1}$ School of Economics and Management, Beijing Jiaotong University, Beijing, China
}

\begin{abstract}
This paper selects panel data from 30 provinces in mainland China from 2003 to 2017, and empirically explores the role and impact of transportation infrastructure on regional tourism economic development. The results found that the national tourism economy was significantly negatively related to railway density and positively related to highway density, but not significant; the number of employees in travel agencies had little effect on the tourism economy; the urbanization rate, industrial structure, and per capita GDP were significantly positively related to the tourism economy. In terms of different regions, the tourism economy in the western region has a significant negative correlation with railway density and a significant positive correlation with highway density. The regression results of the core explanatory variables in the eastern and central regions are not significant. To promote the development of tourism economy, attention should be paid to the multi-factor synergy that affects regional tourism economic growths; transportation development planning should be integrated with regional macro development planning and the overall tourism development planning; promote urbanization development, upgrade the industrial structure to stimulate the level of tourism consumption and give play to its space spillover effect to promote regional cooperation.
\end{abstract}

\section{Introduction}

In the past 40 years of Economic Reform and Open up, tourism has become the main axis of the national strategy, and transportation is the premise and foundation of tourism development, as well as the bridge between tourism supply and demand. At the same time, tourism economic activities have a great impact on the traffic pattern and operation and development. According to Bao Jigang ${ }^{[1]}$, tourism transportation refers to the transportation facilities and services provided for tourists to travel back and forth from the tourist source to the destination, as well as carry out various tourism activities in various places of the tourist destination. As one of the three pillar industries of tourism, tourism transportation is the link between tourists and tourism resources, the important carrier of tourism activities, and plays a vital role in the development of tourism.

At present, accelerating the transformation of economic development mode, optimizing the proportion of various industries in the economy, and improving the contribution rate of the tertiary industry to the economy have become the primary task under the new normal of economy. As an important part of the tertiary industry, tourism has the characteristics of strong relevance, high comprehension and strong industry drive. Therefore, many countries regard tourism industry as the entry point of industrial structure adjustment and the breakthrough of reform, in order to play the leading role of tourism industry and promote the revitalization and sound development of economy.

This article mainly studies the relationship between the construction of transportation infrastructure and the development of tourism economy. Due to the difficulty of obtaining domestic tourism income data, this article uses travel agency operating income as the research object. The research scope includes travel agency operating income data from 30 provinces in Mainland China from 2003 to 2017 (because some of Tibet's data is not available, Tibet is excluded). After that, an inter-provincial panel data model of tourism economic income was established, and railway density and highway density were selected as core explanatory variables, and the number of travel agency employees, urban rate, industrial structure and per capita GDP were included as control variables. Then we can analyse the function of transportation infrastructure to the development of China's tourism economy.

\section{Literature review}

Domestic and foreign scholars have done a lot of research on the impact of transportation infrastructure on the development of regional tourism economy, and there are mainly three different conclusions as follows:

Firstly, transportation infrastructure has a significant impact on the development of tourism economy. For example, Kaul $(1985)^{[2]}$ pointed out that its construction could promote the development of tourist destinations and increase the number of tourists. Su Jianjun et al. (2012)

\footnotetext{
*Corresponding author: 19120735@bjtu.edu.cn
} 
${ }^{[3]}$ used co-integration analysis and Granger causality test to study that there was a certain equilibrium relationship between China's tourism passenger volume and traffic passenger volume. The above literatures mainly included one or more transportation modes or passenger volume in the transportation infrastructure such as highway and railway as input variables into the model, and relatively little considered the influence of other factors on the development of regional tourism economy.

Secondly, the influence of transportation infrastructure on regional tourism economic development is not significant. For example, Zuo Bing $(2011)^{[4]}$ believed that accessibility was an important variable affecting the development of regional tourism economy, and linear regression study found that there was no significant correlation between the impact of transportation accessibility on the development of tourism economy. Li Ruyou et al. $(2015)^{[5]}$ found that the level of transportation infrastructure in China did not have a significant impact on tourism development in the middle level of zoning system. The above literature research shows that no matter what empirical research method is adopted, different transportation modes and levels of transportation infrastructure will have different influences on the region. Therefore, in the research process, it is necessary to divide the region and subdivide the transportation infrastructure to verify its influence on the regional tourism economic development.

Thirdly, the transportation infrastructure has a negative impact on the development of regional tourism economy. The empirical study of Li Ruyou et al. $(2015)^{[5]}$ also concluded that when China's transportation infrastructure level was in the high-level district system, it would had a significant negative impact on the development of tourism economy. It shows that if the transportation infrastructure develops too fast or can't keep up with the development level of regional tourism economy, it will have a restraining effect on the development of regional tourism economy.

\section{Variables, models, and data}

\subsection{Variable selection}

Definitions and symbols of relevant variables are set as follows.

Table1. Variables definition and symbols.

\begin{tabular}{|c|c|c|c|}
\hline & Name & Definition & Symbol \\
\hline $\begin{array}{c}\text { Dependent } \\
\text { variable }\end{array}$ & $\begin{array}{c}\text { Logarithm of travel } \\
\text { agency revenue }\end{array}$ & reflect tourism income & LNR \\
\hline \multirow{4}{*}{$\begin{array}{c}\text { Independent } \\
\text { variable }\end{array}$} & Railway density & railway miles/area of province & RD \\
\cline { 2 - 4 } & Highway density & highway miles/area of province & HD \\
\cline { 2 - 4 } & $\begin{array}{c}\text { Number of travel agency } \\
\text { employees }\end{array}$ & reflecting human capital & L \\
\cline { 2 - 4 } & Urbanization rate & $\begin{array}{c}\text { non-agricultural population/permanent } \\
\text { resident population of the city }\end{array}$ & URB \\
\cline { 2 - 4 } & Industrial structure & proportion of the tertiary industry & IS \\
\cline { 2 - 4 } & GDP per capita & $\begin{array}{c}\text { reflect the level of regional } \\
\text { economic development }\end{array}$ & PGDP \\
\hline
\end{tabular}

\subsection{Data description}

\subsubsection{Overall situation}

As can be seen from the Fig. 1. and Fig. 2., from 2003 to 2017 , both the railway density and the highway density showed an upward trend, but in order of magnitude, the highway density far exceeded the railway density. As shown in Fig. 3., the operating income of China's travel agencies fluctuated greatly. After 2010, the data showed a rapid rising trend.

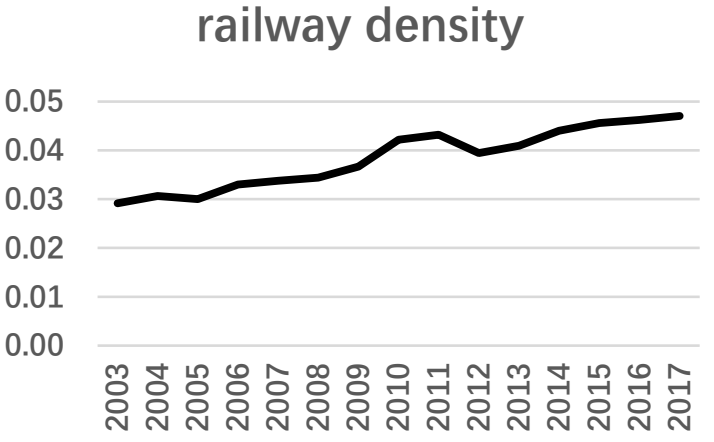

Fig 1. 2003-2017Changes of railway density in China.

\section{highway density}

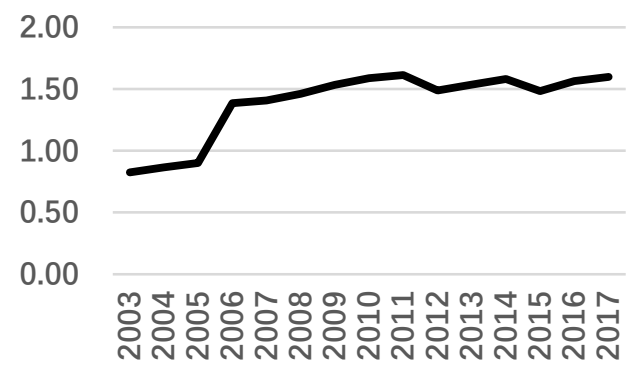

Fig 2 2003-2017Changes of highway density in China.

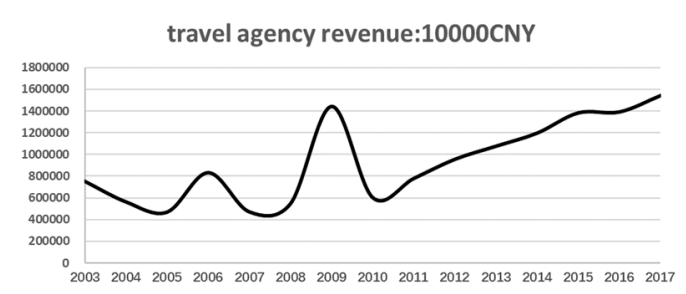

Fig 3 2003-2017Changes in revenue of travel agencies.

\subsubsection{Regional description}

According to Fig. 4., the railway density in the western and eastern China is basically higher than the national level, while the railway density in the central China is far behind the national level, but it keeps a steady rising trend. Fig. 5. shows that the gap between the east and west has been widening in recent years. By comparison, roads have performed better than railway. And travel agency revenue in the east is far higher than in the rest of China according to the Fig. 6 . 


\section{railway density}

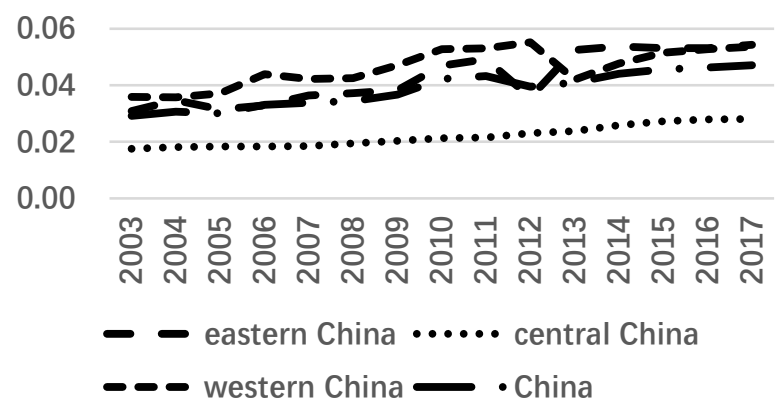

Fig 4 2003-2017Changes of railway density in China.

\section{highway density}

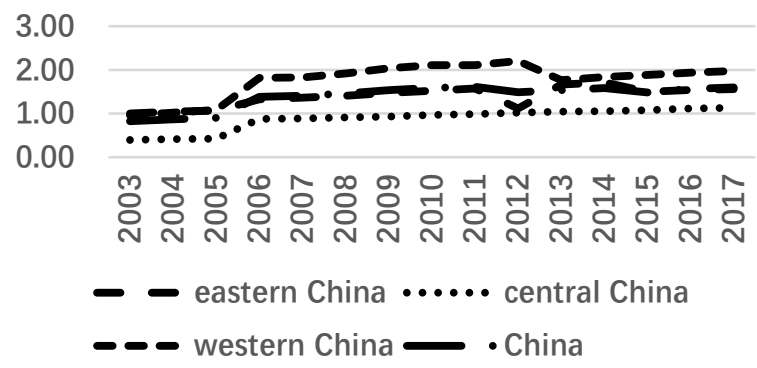

Fig 5 2003-2017Changes of highway density in China.

travel agency revenue:10000CNY

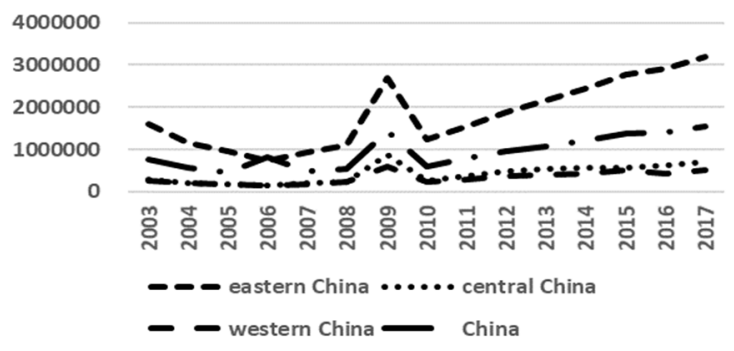

Fig 6 2003-2017Changes in revenue of travel agencies.

\subsection{Panel data test}

The unit root test shows that there is no unit root in the first order difference series, and the panel data series is stable. The co-integration test proves that all the variables involved in this study have long-term stable relationships. After that, the panel data model was selected (the process was appropriately omitted), and the variable intercept fixed effect model was finally established.

$$
L N R_{i t}=c+\beta_{1} R D+\beta_{2} H D+\beta_{3} L+\beta_{4} U R B+\beta_{5} I S+\beta_{6} P G D P+\mu_{i t}
$$

\section{Results \& Discussion}

\subsection{Overall regression results}

According to the regression results of regional tourism economy in Table 2, regional tourism economy is significantly negatively correlated with "railway density", while it is positively correlated with "road density", but not significantly. From the perspective of human capital, the regression coefficient of the variable "number of travel agency employees" is 0.0001 . Although this variable is significant, it has little effect on tourism economy. "Urbanization rate" is significantly positively correlated with the tourism economy, further verifying that the regional urbanization level has a profound impact on the development of tourism. "Industrial structure" is also positively correlated with the tourism economy, which meets the expectation, that is, the higher the proportion of the three industries in a region, the better the development of the tourism economy. The regression coefficient of "per capita GDP" variable is 0.1578 , which further verifies that the level of economic development is the driving force and guarantee for the development of tourism economy.

Table2. Overall regression results.

\begin{tabular}{|c|c|c|c|}
\hline Variables & Coefficient & t value & p value \\
\hline Constant & 10.5440 & 36.3930 & 0.0000 \\
\hline Railway density & -2.1918 & 1.4496 & 0.0784 \\
\hline Highway density & 0.0252 & 0.5354 & 0.5927 \\
\hline $\begin{array}{c}\text { Number of travel agency } \\
\text { employees }\end{array}$ & 0.0001 & 11.0426 & 0.0000 \\
\hline Urbanization rate & 2.3188 & 4.2980 & 0.0000 \\
\hline Industrial structure & 1.2849 & 2.5218 & 0.0120 \\
\hline GDP per capita & 0.1578 & 8.5999 & 0.0000 \\
\hline adjusted R & 0.9258 & & \\
\hline F value & 161.0584 & & \\
\hline F vlaue-p value & 0.0000 & & \\
\hline
\end{tabular}

\subsection{Regional regression results}

Table 3 shows that the regression results of the two core explanatory variables in the eastern, central and western regions are significantly different, while those in the eastern and central regions are not significant. In western China, "railway density" is significantly negatively correlated with tourism economy, and "highway density" is significantly positively correlated with tourism economy. According to the regression results of "the number of travel agency employees", although all of them are significant, the regression coefficient is close to 0 , indicating that the number of travel agency employees does not play an obvious role in promoting tourism economy. In terms of " Urbanization rate ", only the central region is significant. In terms of "industrial structure", only the eastern region is significant. The variables of "per capita GDP" in the eastern, central and western regions are all significantly positively correlated with tourism economy at the level of $1 \%$. 
Table3. Regional regression results.

\begin{tabular}{|c|c|c|c|}
\hline Variables & Eastern & Central & Western \\
\hline Constant & $10.8947^{* * *}$ & $9.6580^{* * *}$ & $10.5440^{* * *}$ \\
\hline Railway density & 0.3098 & 9.1131 & $-7.7394^{* *}$ \\
\hline Highway density & -0.0193 & 0.1858 & $0.1780^{* *}$ \\
\hline $\begin{array}{c}\text { Number of trave1 agency } \\
\text { employees }\end{array}$ & $0.0010^{* * *}$ & $0.0001^{* * *}$ & $0.0000^{* * *}$ \\
\hline Urbanization rate & 1.5227 & $3.9224^{* * *}$ & 1.4194 \\
\hline Industrial structure & $2.63503^{* *}$ & -0.0023 & 0.7462 \\
\hline GDP per capita & $0.120714^{* * *}$ & $0.1704^{* * * *}$ & $0.2261^{* * *}$ \\
\hline adjusted $R^{2}$ & 0.9138 & 0.8665 & 0.9379 \\
\hline F value & 109.6009 & 60.4039 & 151.0063 \\
\hline Fv laue-p value & 0.0000 & 0.0000 & 0.0000 \\
\hline
\end{tabular}

The above regression results show that the influence of transportation infrastructure on tourism development cannot be generalized, but needs to be analysed in different regions and different situations. Traditional "traffic condition is the bottleneck factor in the development of regional tourism" and "traffic to a positive role in promoting the development of regional tourism" early know form in Chinese tourism development, such as the stage of China's transportation infrastructure spending less, weak regional accessibility, at this time, increase investment in transport infrastructure, enhance the regional accessibility, indeed can promote the rapid development of regional tourism. However, with the continuous improvement of transportation infrastructure, the level of regional accessibility can basically meet the needs of tourism development. Areas with rich tourism resources and good regional conditions should focus on the development of tourism, making it a pillar industry in the national economy. However, the regions lacking tourism resources develop other industries by using good traffic conditions. At this time, the positive promoting effect of transportation infrastructure on regional tourism development is relatively weakened or changed from significant to insignificant.

The improvement of transportation infrastructure is conducive to reducing transportation costs and transaction costs, developing inter-regional division of labour and cooperation, and forming the spatial aggregation of labour, capital and technology through unblocking resource circulation channels, thus affecting the change of regional industrial structure. On the one hand, the further construction and improvement of transportation infrastructure will produce "crowding out effect" on tourism by promoting the development of other industries in the national economy, and the faster development of other industries will "restrain" the development of tourism. On the other hand, tourism industry has a wide range of industrial connections, and the development of related industries induced by the improvement of transportation infrastructure will react on tourism industry, infiltrate and integrate with tourism industry to form new industrial forms and thus produce "crowding in effect". However, the integration of China's tourism industry is still in its initial stage, the integration of tourism and other industries, especially non-service industries, is not mature enough, and the integration depth needs to be strengthened. The supporting role of relevant industries for tourism is still in creating a good external environment for it, and the industrial integration effect has not been fully reflected.

\section{Conclusions \& Suggestions}

\subsection{Conclusions}

Based on the panel data of 30 provinces in the Chinese mainland from 2003 to 2017, this paper empirically explores the role and impact of transportation infrastructure on regional tourism economic development. The results show that the national tourism economy is negatively correlated with the railway density and positively correlated with the highway density, but not significantly. The number of travel agency employees has little effect on tourism economy. The urbanization rate, industrial structure and per capita GDP are significantly positively correlated with tourism economy. In terms of regions, railway density in western China is significantly negatively correlated with tourism economy and positively correlated with highway density, while the regression results of core explanatory variables in eastern and central China are not significant. Possible explanations for the conclusion of this paper are as follows: first, the more developed the transportation infrastructure is, the more likely it is to facilitate the outflow of tourists in the region, shorten their stay time in the region and reduce consumption opportunities, which may produce negative spillover effect in the region. Second, the further construction and improvement of transportation infrastructure will produce "crowding out effect" on tourism by promoting the development of other industries in the national economy, and the faster development of other industries will "restrain" the development of tourism.

\subsection{Suggestions}

Firstly, this study shows that China should pay attention to the synergistic effect of multiple factors that have an impact on regional tourism economic growth while developing tourism. In terms of regional development policy, we should adhere to the principle of promoting advantages and eliminating disadvantages, and realize the deep integration of transportation infrastructure and these factors through further digging and rationalization of resources, so as to jointly promote the development of regional tourism.

Secondly, the role of transportation infrastructure in regional tourism development should be correctly understood and reflected in regional development planning. It is necessary to give full play to the leading role of the government and coordinate the relationship between the tourism department and the transportation department. The formulation of the transportation development plan should be linked with the regional macro development plan and the overall planning of tourism development. At the same time, macro-control should be strengthened to make the capital flow of 
tourism and transportation infrastructure construction conform to the law of regional development, and to avoid the blind large-scale investment and construction of transportation infrastructure in order to develop tourism.

Thirdly, urbanization development and industrial structure upgrading should be promoted to stimulate the level of tourism consumption and give full play to its spatial spillover effect to promote inter-regional cooperation. Therefore, the government should actively promote the integration of urban and rural areas, continue to steadily push forward the industrial structure upgrade, at the same time, improve the pension, employment, health care and education, such as social security system, enhances the risk resistance ability of the residents in the future, further stability continue to release the residents' tourism consumption ability.

\section{References}

1. Bao, J., Chu, Y.(1999) Tourism Geography. Higher Education Press, Beijing.

2. Kaul, R. N, Dynamics Of Tourism: A Trilogy. New Delhi: Sterling Publishers Private Limitied,1985.

3. Su, J., Sun, G., Zhao, D.(2012) The Impact of Great Changes of Transportation on the Development of China's Tourism Industry and Division of Regional Types. Tourism Tribune, 27(06):41-51.

4. Zuo, B.(2011) An Empirical Study of the Factors Influencing the Tourism Economic Growth of China. Journal of Business Economics, 10:82-90.

5. Li, R., Huang, C. (2015) Research on the Impact of Traffic Infrastructure on Regional Tourism Development in China: Based on the Evidence of Threshold Regression Model. Tourism Science, 29(02):1-13+27. 